\title{
THE DETERMINATION OF THE ALPHA-CELLULOSE CONTENT AND COPPER NUMBER OF PAPER
}

\author{
By John O. Burton and Royal H. Rasch ${ }^{1}$
}

\section{ABSTRACT}

In determining the permanence of a paper it is important to know the purity of the cellulose composing it. The tests most commonly used for the determination of the purity of cellulosic materials are the alpha cellulose and copper number tests. The alpha-cellulose test is based upon the assumption that unmodified cellulose is insoluble in a mercerizing caustic solution. This insoluble portion is termed "alpha cellulose." The copper-number test is based upon the quantitative reduction of an alkaline copper solution by the degraded celluloses of the sample. The copper number is the weight of copper so reduced by a definite weight of the sample.

Both of these tests have been highly developed for the analysis of cellulosic materials in a loose, fibrous form, such as paper pulp. But the fibers of paper are packed into a dense, compact sheet and, hence, methods which can be applied to other forms of cellulose can not be applied to paper. Also, papers contain several noncellulosic constituents which must be taken into account. Methods which have been proved reliable for the analysis of other forms of cellulosic materials have been modified by the bureau to make them applicable to paper testing. The modification considered of prime importance is the reduction of the sample to a cotton-like form by means of mechanical disintegration. It is also important to correct the results for the amounts of sizing and loading materials in the paper. Several minor details of the methods have been altered for purposes of simplicity and increased accuracy. By the use of the alpha-cellulose method duplicate determinations of the percentage of alpha cellulose agree within 0.3 . Duplicate results obtained with the copper-number method seldom vary more than 1 per cent from their mean.

\section{CONTENTS}

Page

603

605

606

606

606

606

607

613

613

614

615

616

619

\section{INTRODUCTION}

The determinations of the alpha-cellulose content and copper number are used to a considerable extent in evaluating the purity of cellulose materials. The alpha-cellulose content of a cellulosic material is that part which is insoluble in a sodium hydroxide solution 
of mercerizing strength under certain specified conditions. The copper number is the weight of copper in grams, reduced as cuprous oxide from an alkaline copper solution by a given amount of the cellulosic material. The purer forms of cellulose are characterized by a high content of alpha cellulose and a low copper number. The alphacellulose content is regarded as the amount of unmodified cellulose which the material contains. The remainder of the cellulose material may be composed of several substances, such as naturally occurring waxes and resins, lignin, pentosans, and modified forms of cellulose, but the chief constituents are the modified forms of cellulose. These modified celluloses are characterized by their power to reduce copper from alkaline copper solutions. The quantity of copper which they will reduce depends upon their amount and the extent to which they have been modified. Thus the copper number arises from these modified forms of cellulose and simultaneously measures their amount and degree of modification.

These determinations are used as a matter of routine procedure in testing the raw cellulose materials, such as cotton and wood fibers, used in the manufacture of rayon, lacquers, guncotton and other cellulose products. The viscose industry has long realized the close connection between the purity of the cellulose materials and the quality of the product. There is without doubt a similar relation in the manufacture of paper. The stability of paper, and in many cases its strength, appears to be directly related to its cellulosic purity as measured in terms of alpha cellulose and copper number. The use of these determinations for judging the quality of fibrous raw materials used for paper making and for testing the probable permanence of papers is rapidly increasing. As the cellulose of paper-making fibers is usually degraded to some extent in the paper-making process, such as by oxidation or hydration in the cooking, bleaching, and beating, determinations of alpha cellulose and copper number are also used to some extent as control tests. As these modified celluloses are considered to be quite impermanent and a possible cause of deterioration, it is important to know not only the content of unmodified cellulose in a paper or a paper-making material, but also to know the degree of the modification as expressed by the copper number.

In its research on the permanence of paper the National Bureau of Standards makes extensive use of the alpha cellulose and copper number determinations. In the course of this work the methods described in the literature for these determinations were found unsuitable for the analysis of paper, having been designed more particularly for soft, readily-absorbent materials such as are used for viscose products. 'They could not be successfully applied to more compact and resistant materials such as paper and certain paper-making fibers.

Experimental study of the methods available resulted in the development of modified testing procedures which appear to be more satisfactory for the analysis of paper and paper-making fibers. Following are descriptions of the modified methods as they are now being used by the bureau, and of the experimental studies made in connection with their development. 
B. S. Journal of Research, RP295

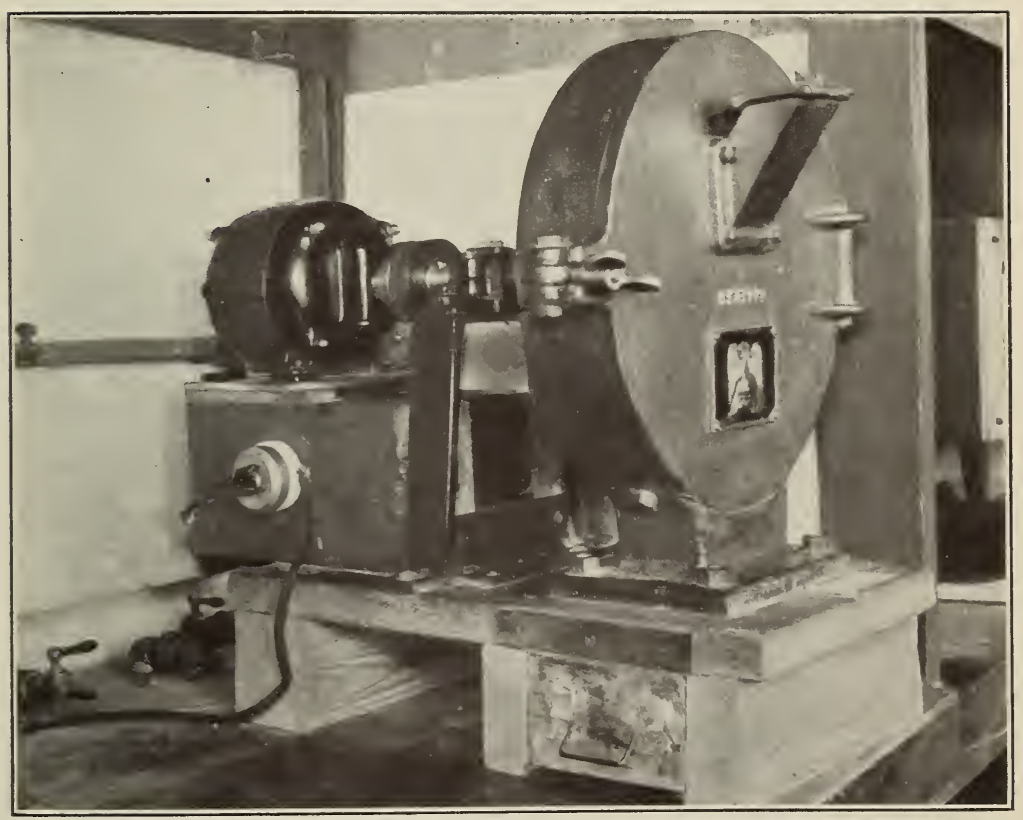

Figure 1.-Paper disintegrator 


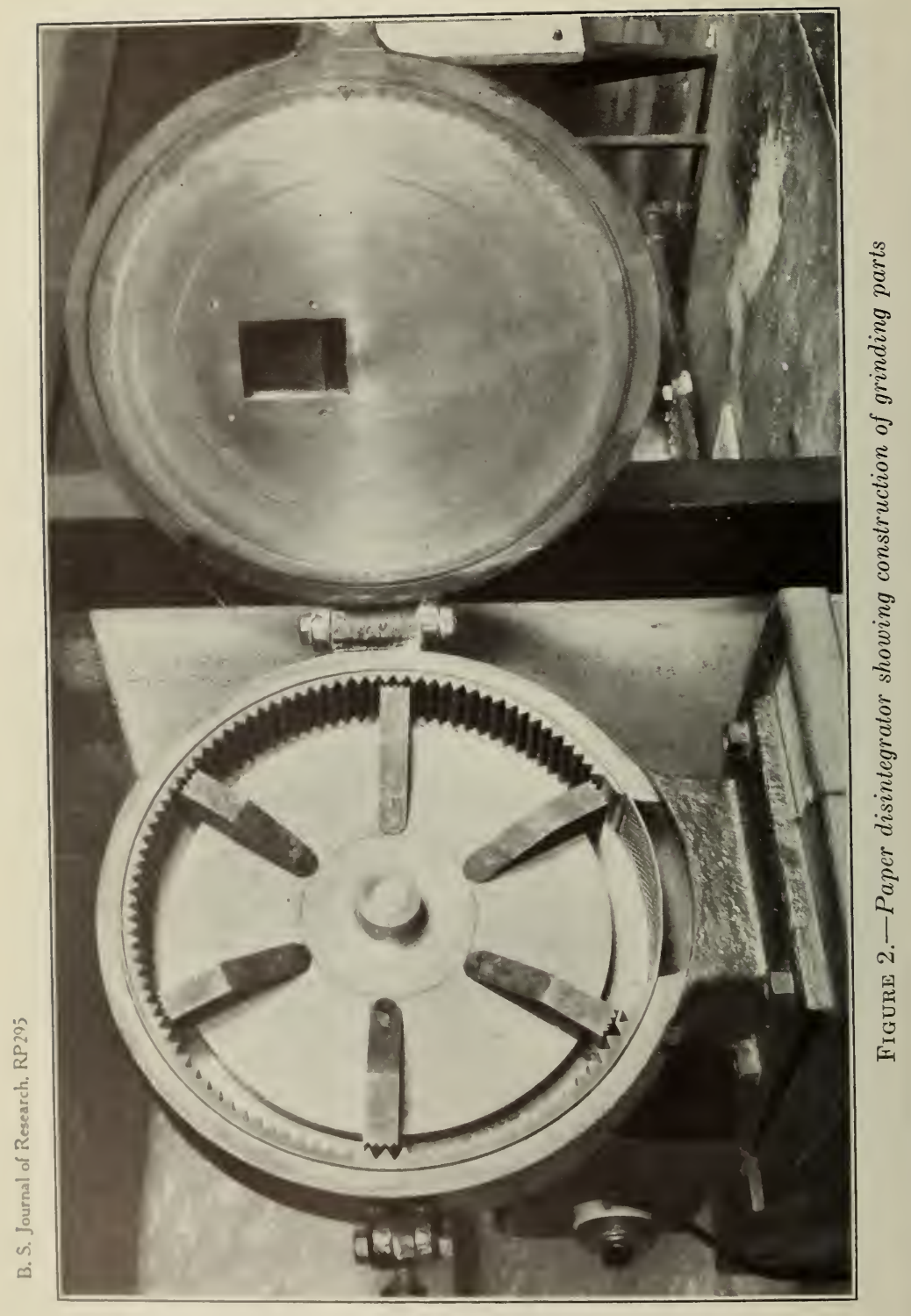




\section{PREPARATION OF THE SAMPLE}

The basic constituent of papers is cellulose, but in a determination of their chemical properties they differ markedly from most other cellulosic materials in that the fibers are closely packed in to a dense, compact sheet and are protected from the action of chemical agents by a covering of rosin. For this reason the bureau has adopted the suggestion of Kohler and $\mathrm{Hall}^{2}$ and for chemical determinations such as these, reduces all paper to a uniform fibrous condition by the use of a grinder.

The grinder used was designed by Gösta Hall, and is similar to the one used at the Swedish Government Testing Institute. (See figs. 1 and 2.). Several of these grinders are in use in this country and abroad. The grinder consists of a 12-inch rotor revolving inside a steel housing at a speed of 1,700 revolutions per minute. The rotor is fitted with six serrated steel lugs, and the inner circumference of the steel housing is also serrated. The rotor teeth clear those of the housing by a sixteenth of an inch. The paper is introduced in the form of $1 / 2$-inch strips through a hopper and is then carried by centrifugal force to the space between the rotor teeth and those of the steel housing where it is disintegrated. The cotton-like material thus formed is ejected through a 10-mesh wire screen and collected in a receptacle in the base of the apparatus. This method of grinding possesses the advantages of rapidity, and absence of a noticeable rise in temperature and of contamination. Most of the grinding is done by impact, the paper being thrown against the teeth of the steel housing with sufficient force for disintegration. Thus there is no sustained action on the fibers and excessive bruising and crushing are avoided.

The disintegrated paper is spread loosely in trays and allowed to attain equilibrium with the moisture of the atmosphere in the vicinity of the balance upon which the sample is to be weighed. Samples should be exposed to this atmosphere for at least six hours. This procedure has been found to be superior to conditioning the sample in a closed container as in many cases the relative humidity of the atmosphere in the container and that of the atmosphere in which the sample must be weighed differ sufficiently to cause the sample to continually change in weight during the weighing: A constant temperature and humidity room in which weighings can be made is very useful for conditioning samples.

Papers containing sizing or loading materials must be analyzed for the amounts of these materials, as the results are based on the weight of the fibrous material in the paper and not on the weight of the paper itself. The analysis of the paper for sizing materials may be made on either the sheet or disintegrated form of the sample. The analysis for loading materials should be made on the disintegrated paper, as the amount of loading materials in this form may differ from the amount in the original paper because of loss during the grinding operation. The grinding tends to free the filler from the fibers so that it is rather loosely held. Although some of the filler is usually lost, that which is retained by the fibers will remain quite uniformly distributed throughout the sample if care is taken to avoid excessive shaking and handling of the disintegrated paper. This is true if the filler content is less than about 12 per cent. If it is greater than this it may be difficult

2 Kohler and Hall, Acidity in Paper, The Paper Ind., 7, No. 7; October, 1925. 
to obtain a unitorm sample. The moisture content of the sample is also determined. The analyses for sizing materials, filler, and moisture are made by the methods of the Technical Association of the Pulp and Paper Industry. ${ }^{3}$

The weights of the samples used in the alpha-cellulose and coppernumber determinations are corrected for moisture content, ash, and sizing materials, and the results are calculated on this corrected weight. Table 4 shows the magnitude of the correction for the sizing materials in the sample.

\section{THE DETERMINATION OF THE ALPHA-CELLULOSE CONTENT OF PAPER}

\section{DEFINITION OF ALPHA-CELLULOSE AND ORIGIN OF THE METHOD}

By alpha cellulose is meant that part of cellulosic materials which is insoluble in a snlution of sodium hydroxide of mercerizing strength under definite conditions for a definite time. Cross and Bevan ${ }^{4}$ first mentioned the analytical use of mercerizing caustic for the isolation of "normal cellulose." Data were later produced to show that no so-called pure cellulose was entirely insoluble in mercerizing caustic, but the principle used by Cross and Bevan for isolating normal cellulose was found to be applicable to the testing of cellulosic materials for unmodified cellulose or "alpha cellulose." Many methods have been devised for the determination of alpha cellulose, but the one most commonly used is that of Jentgen ${ }^{5}$ or some modification thereof. The method described here is based on that of Jentgen and modifications of his method suggested by Parsons ${ }^{6}$ and Ross.

\section{PREPARATION OF THE MERCERIZING SOLUTION}

The mercerizing solution consists of an aqueous solution of sodium hydroxide (cp grade) containing 17.5 per cent sodium hydroxide by weight, having a specific gravity of 1.197 at $15^{\circ} \mathrm{C}$. The c. p. grade of sodium hydroxide usually contains 1 to 2 per cent sodium carbonate, which must be removed. This is accomplished according to directions given by Clark. ${ }^{8}$ The required weight of sodium hydroxide sticks is dissolved in an equal weight of water and the solution allowed to stand in a closed vessel for several days, during which time the sodium carbonate will precipitate. The solution is filtered through a thick mat of asbestos or a hardened filter paper and diluted to the correct concentration with distilled water, which has been recently boiled to expel carbon dioxide. Care must be taken when handling the solution that it is exposed to the atmosphere as little as possiblo to prevent the absorption of carbon dioxide.

\section{PROCEDURE}

Weigh accurately approximately $5 \mathrm{~g}$ of the sample, prepared in the manner previously described, in a weighing bottle. Calculate the corrected weight of sample by subtracting from the original air-dry weight the weights of mositure, ash, and sizing materials. Transfer

\footnotetext{
2Pnper Testing Methods, published for the Technical Association of the Pulp and Paper Industry,

New York, I ockwood Trade Journal Co.; 1928

- Cross and Bevan, Researches on Cellulose, 3, p. 22; 1905-1910.

Jentgen, Kunststofle, 1, p. 165; 1911.

- Parsons, Paper Trade Jour., 82, No. 8, p. 211 (Technical Section, p. 105); 1926.

Ross, Iresearch Notes, Canadian Pulp and Paper Association, 1, pp. 37-57; 1926.

- ('lark, The Determination of Hydrogen Ions, Baltimore, The Williams \& Wilkens Co., p. 195; 1928.
} 
the accurately weighed sample to a $400 \mathrm{ml}$ beaker of resistant glass, such as Pyrex, and place the beaker in a constant temperature bath at $20^{\circ} \mathrm{C}$. After the beaker has attained the temperature of the bath add by means of a pipette $50 \mathrm{ml}$ of the sodium hydroxide solution, the temperature of which has been adjusted to $20^{\circ} \mathrm{C}$. Note the time immediately after the addition of the mercerizing solution. Macerate the sample well with a flattened glass stirring rod. Add another $50 \mathrm{ml}$ portion of the sodium hydroxide solution and repeat the maceration. Allow the solution to stand for 30 minutes from the time of the first addition of caustic soda solution. In the meantime fit a filter flask with a $7.5 \mathrm{~cm}$ Büchner funnel containing a circular piece of cloth as a filtering medium. Use a high-grade cotton cloth of fine texture for this purpose. Nainsook has been found to be satisfactory. Dry the cloth in an oven at $105^{\circ} \mathrm{C}$. until the weight is constant and record the dry weight.

At the end of the 30-minute period dilute the contents of the beaker with $250 \mathrm{ml}$ of distilled water and filter through the cloth, using mild suction. Pack the mat thus formed with the stirring rod and wash with an additional $125 \mathrm{ml}$ of distilled water. Return the filtrate to the mat and refilter to retain any fine fibers which may have passed through when the mat was first formed. Then wash with $625 \mathrm{ml}$ of distilled water added in small portions, packing the mat occasionally to prevent the formation of a channel around its edges. All of the wash water is used at $20^{\circ} \mathrm{C}$. After the washing, disconnect the suction and add $100 \mathrm{ml}$ of 20 per cent acetic acid, allowing it to soak through the mat for five minutes. Remove the acetic acid by means of suction and complete the washing with 1 liter of boiling distilled water, added in small portions. Place the mat and filter cloth on a watch glass or Petri dish and dry at $50^{\circ}$ to $60^{\circ} \mathrm{C}$. until most of the moisture has been removed. Then transfer them to a glass-stoppered weighing bottle and dry to constant weight at $105^{\circ} \mathrm{C}$.

If no filler were present in the paper this weight, less that of the filter cloth, would be the weight of the alpha cellulose. If the paper contained filler, determine the amount retained in the alpha-cellulose residue by igniting the residue and weighing the ash. The ignition is carried out in the manner described in the method of the Technical Association of the Pulp and Paper Industry for the quantitative determination of filler in paper. ${ }^{9}$ Subtract the weight of the ash from the weight of the alpha-cellulose residue. The alpha cellulose is reported as the percentage of the corrected weight of the sample.

\section{DISCUSSION OF THE METHOD}

In common with all other test methods, the value of a method for determining the alpha-cellulose content of a material depends upon the accuracy and reproducibility of the measurements. Also, because of the use of the determination as a control test in several industries where a large number of samples must be analyzed, the analysis should be as simple and rapid as possible.

The accuracy of the method is difficult to determine because of the empirical and arbitrary definition of alpha cellulose. As was stated before, alpha cellulose is that part of cellulosic materials which resists the action of mercerizing caustic under definite conditions for a specified time. With a definition such as this the only criterion

? See footnote 3, p. 606. 
of accuracy appears to be reproducibility. If the conditions specified in the definition are fulfilled in every detail and the results of an analysis can be duplicated, those results are, by definition, the accurate value of the alpha-cellulose content of the material. Thus, providing the details of the procedure are followed, the value of the method is determined by the reproducibility of the results. It may be seen from Table 1 that consistent results are obtained by the use of this method. Two analysts were able to duplicate their own and each other's results satisfactorily on a wide variety of papers. These papers were representative of several of the more common papermaling fibers. Some were sized with rosin, some with both glue and rosin, while others were unsized. Sample 6 contained 8 per cent of clay filler. Sample 1, an unsized paper made in the bureau mill from new unbleached cotton rags, which were a quite pure form of cellulose, had an alpha-cellulose content commensurate with its purity.

TABLE 1.-Accuracy and reproducioitity of the alpha-cellulose method

\begin{tabular}{|c|c|c|c|c|c|c|c|c|c|}
\hline \multirow[b]{2}{*}{$\begin{array}{l}\text { Sam- } \\
\text { plo } \\
\text { No. }\end{array}$} & \multirow[b]{2}{*}{ Fiber composition } & \multirow[b]{2}{*}{ Sizing material } & \multicolumn{3}{|c|}{ Analyst No. 1} & \multicolumn{3}{|c|}{ Analyst No. 2} & \multirow{2}{*}{$\begin{array}{l}\text { Differ- } \\
\text { ence be- } \\
\text { tween } \\
\text { ana- } \\
\text { lysts }\end{array}$} \\
\hline & & & $\begin{array}{l}\text { Alpha } \\
\text { cellu- } \\
\text { lose }\end{array}$ & $\begin{array}{c}\text { Aver- } \\
\text { age }\end{array}$ & $\begin{array}{l}\text { Differ- } \\
\text { ence }\end{array}$ & $\begin{array}{l}\text { Alpha } \\
\text { cellu- } \\
\text { lose }\end{array}$ & $\begin{array}{c}\text { Aver- } \\
\text { ago }\end{array}$ & $\begin{array}{l}\text { Differ- } \\
\text { ence }\end{array}$ & \\
\hline & & & Per & $\begin{array}{l}\text { Per } \\
\text { cent }\end{array}$ & $\begin{array}{l}\text { Per } \\
\text { cent }\end{array}$ & $\begin{array}{l}\text { Per } \\
\text { cent }\end{array}$ & $\begin{array}{l}\text { Per } \\
\text { cent }\end{array}$ & $\begin{array}{l}\text { Per } \\
\text { cent }\end{array}$ & $\begin{array}{l}\text { Per } \\
\text { cent }\end{array}$ \\
\hline 1 & $100 \mathrm{rag}-$ & Unsized.. & $\left\{\begin{array}{l}98.26 \\
98.17\end{array}\right.$ & 98.21 & 0.09 & $\begin{array}{l}97.97 \\
98.21\end{array}$ & 98.09 & 0.24 & 0.12 \\
\hline 2 & - & Rosin and glue. & $\begin{array}{l}89.15 \\
\text { S9.23 }\end{array}$ & 89.19 & .08 & $\begin{array}{l}89.46 \\
89.23\end{array}$ & 89. 34 & .23 & .15 \\
\hline 3 & $\left\{\begin{array}{l}100 \text { purified wood } \\
\text { fiber. }\end{array}\right\}$ & Unsized.- & $\begin{array}{l}91.65 \\
91.82\end{array}$ & 91.74 & .17 & $\begin{array}{l}92.20 \\
92.05\end{array}$ & 92.12 & .15 & .38 \\
\hline 4 & -...do do & Rosin and glue... & $\begin{array}{l}88.14 \\
88.43\end{array}$ & 88.29 & .29 & $\begin{array}{l}88.31 \\
88.57\end{array}$ & 88.45 & .23 & .16 \\
\hline 5 & 100 sulphito $\ldots . . .$. & Rosin & $\begin{array}{l}80.21 \\
80.23\end{array}$ & 80.22 & .02 & $\begin{array}{l}79.87 \\
80.14\end{array}$ & 80.00 & .27 & .22 \\
\hline \multirow[t]{2}{*}{16} & 40 sulphite; 60 soda & do & $\begin{array}{l}65.33 \\
65.30\end{array}$ & 65.32 & .03 & $\left\{\begin{array}{l}66.03 \\
66.06\end{array}\right.$ & 66.01 & .03 & .72 \\
\hline & A veruge & & & & .11 & & & .19 & .29 \\
\hline
\end{tabular}

I This paper contained clay filler.

The method is quite rapid. Two determinations on a given sample may be mado in parallel. The mercerizing solution may be added to the next two samples during the 5-minute immersion of the first two in acetic acid. This procedure may be repeated, thus completing two determinations about every 45 minutes, exclusive of the time required for the weighing and drying operations. The method is quite simple. but close attention to detril is required throughout the analysis. This is especially true of the control of the temperature.

Screral details of the method were investigated. One of these was the offect of mechanical grinding upon the value obtained for the alphacollulose content. 'The data in 'Table 2 show that the determined value of the alpha-cellulose content of a paper is dependent upon the form in which the paper is analyzed, $1 / 2$-inch squares giving a higher value than is obtrined when the paper is disintegrated. This difiermec is found in all papers, but it is not constant for all, being less for the softer papers. Providing the sample is disintegrated without heating, this difference may be due to the difference in the amount of surface exposed in the two eases. When the paper is analyzed in the ground form the measured value of the alpha-cellulose content may be 
B. S. Journal of Research, RP205

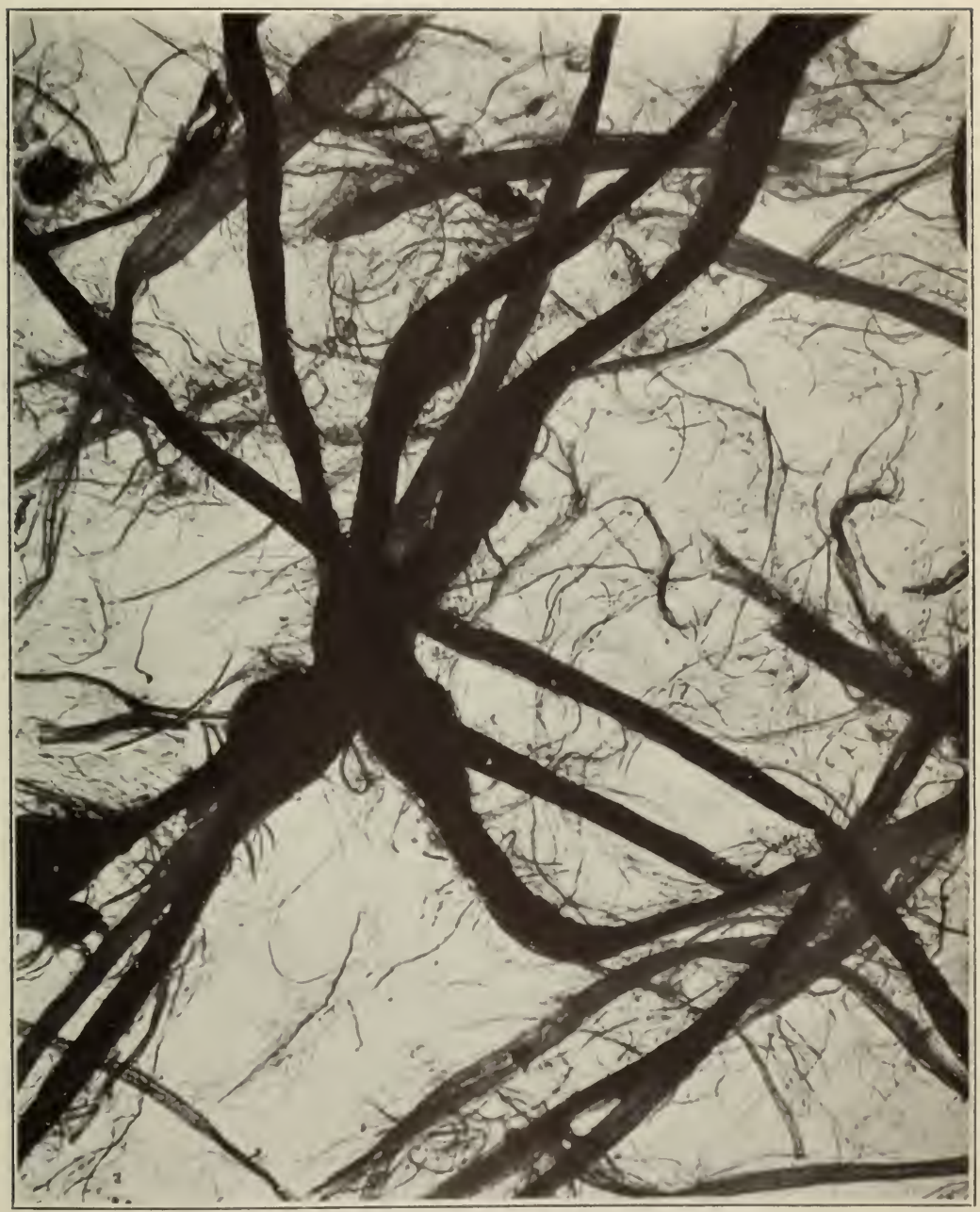

Figure 3.-Fibers from unground rag bond paper. $\quad \times 100$ 


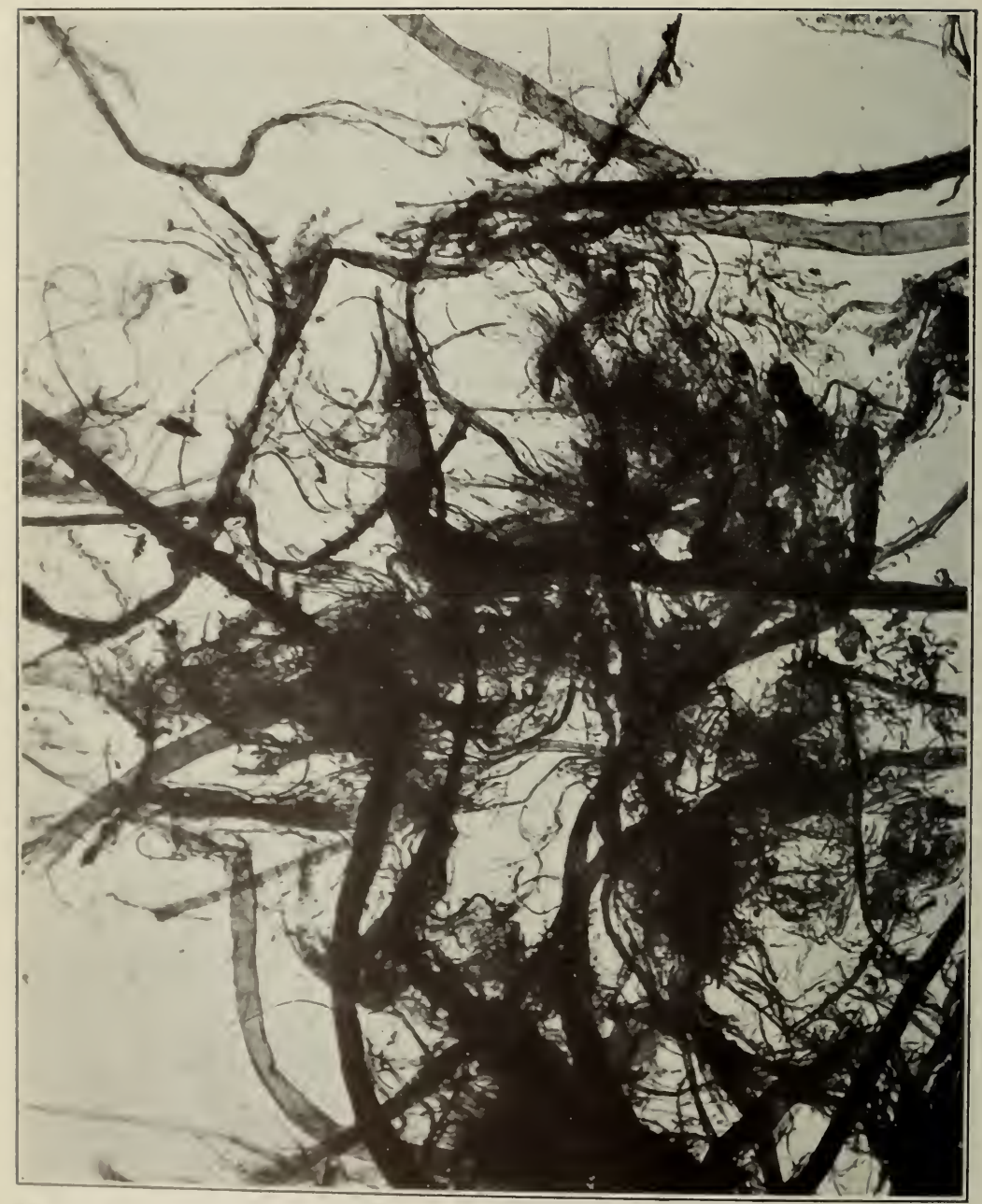

FiGus: 4.-Fibers from rug bond paper after being ground in paper disintegrator. $\times 100$ 


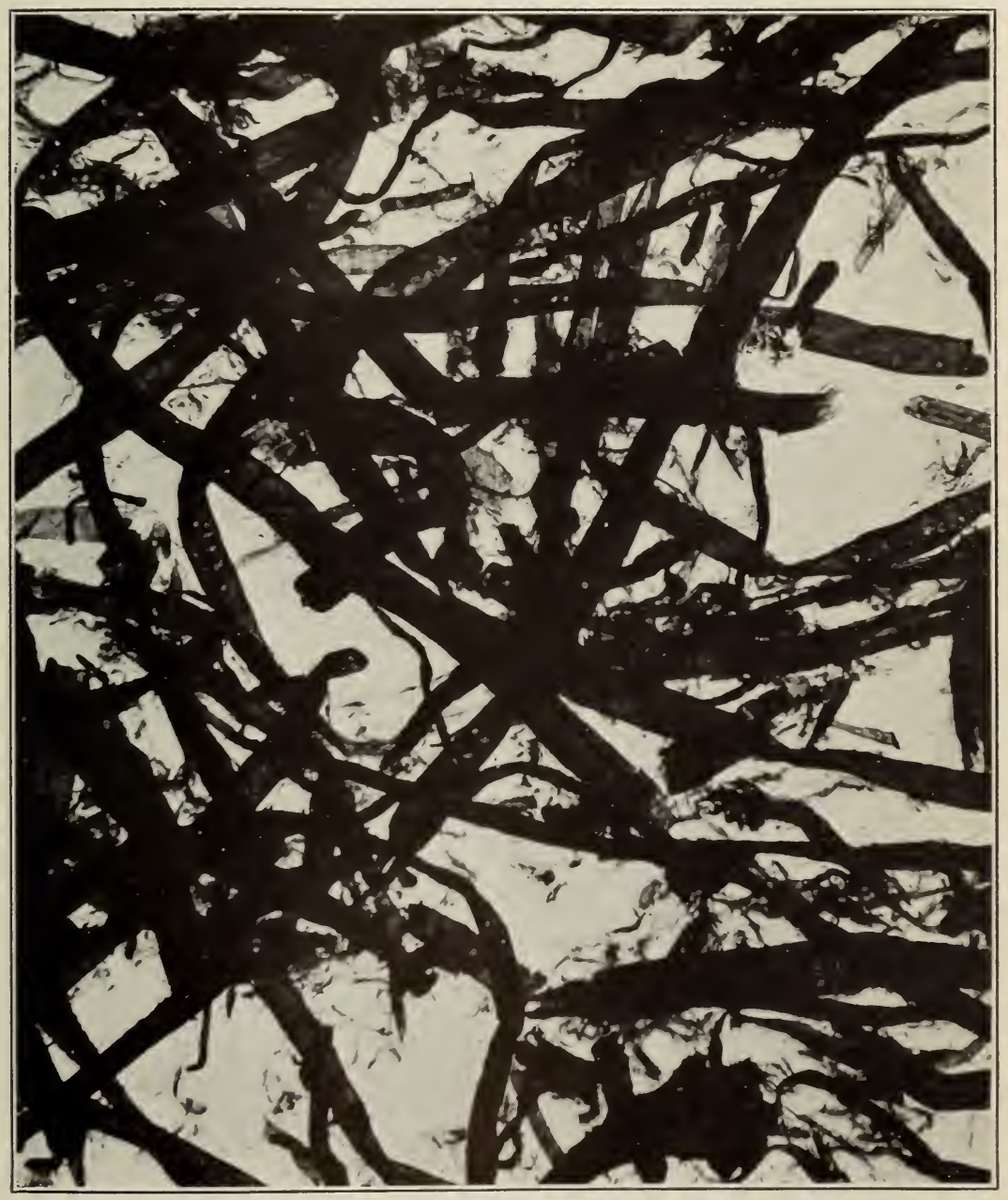

Figure 5.-Fibers from unground sulphite bond paper. $\times 100$ 


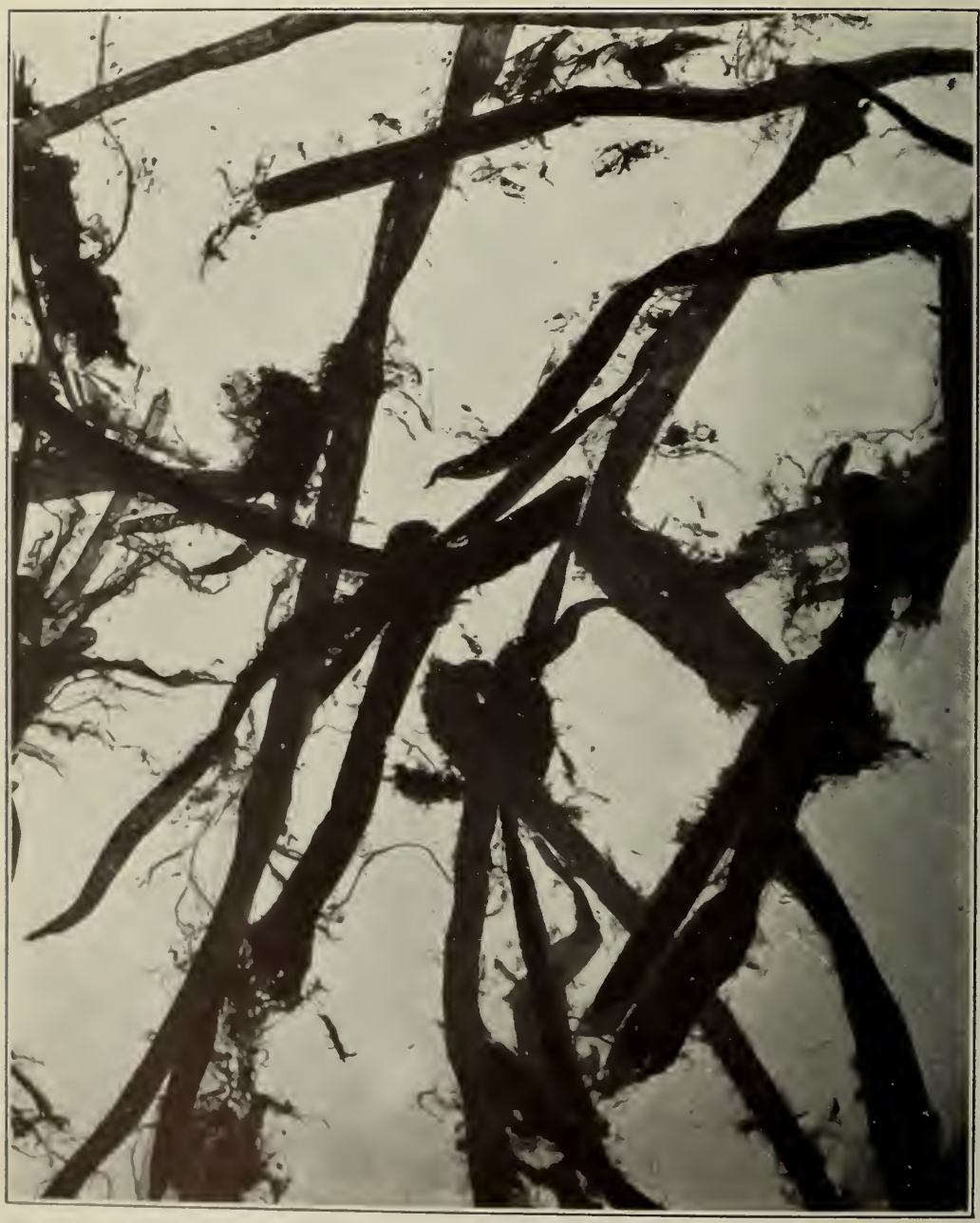

Fuvin: 6.-Fibers from sulphite bond paper after being ground in paper disintegrator. $\times 100$ 
low because of reduced particle size and consequent increased rate of solution in the alkali; and when the squares are used, the measured value may be high because of incomplete reaction with the alkali. Photomicrographs of rag and wood fiber's, after being subjected to the action of the grinder, showed that the fibers were well separated from one another, but that there was no excessive crushing and breaking of the fibers. (See figs. 3, 4, 5, and 6). On the other hand, the data given in Table 2 show that the incomplete reaction of the alkali with the sample in the form of cut squares is the cause of the difference.

If incomplete reaction between the cellulose and alkali were the cause, the difference between the measured alphr-cellulose contents of samples in the form of squares and in the ground form should increase as the hardness of the paper increases. This point was investigated by making by hand papers of varying degrees of hardness from three kinds of pulps. The beating process results in the formation of a gelatinous form of the cellulose material which, when dried, imparts to the finished paper such properties as resistance to liquids, increased density, smoother texture, and other properties usually associated with hardness in paper. As continued beating results in greater hardness, varying the length of the beating period is a convenient method of obtaining papers of different degrees of hardness from the same stock. The three kinds of fibers-kraft, sulphite, and highly purified wood fiber-were beaten in a 2-pound beater until they were well hydrated. Samples were removed from the beater at four different intervals-before any appreciable hydration had taken place, twice during the beating, and at the end of the beating period - and made into hand sheets on a sheet mold. ${ }^{10}$ Thus papers of varying degrees of hardness were obtained from each kind of fiber, the hardness increasing with the time of beating. Each set was divided in to two lots, one lot being cut into one-half inch squares and the other being mechanically disintegrated. An alpha-cellulose determination was then made on all of the sets of hand sheets in the two forms The results are given in Table 2 .

TABLE 2.-Effect of the hardness and the form of the paper on the alpha-cellulose determination

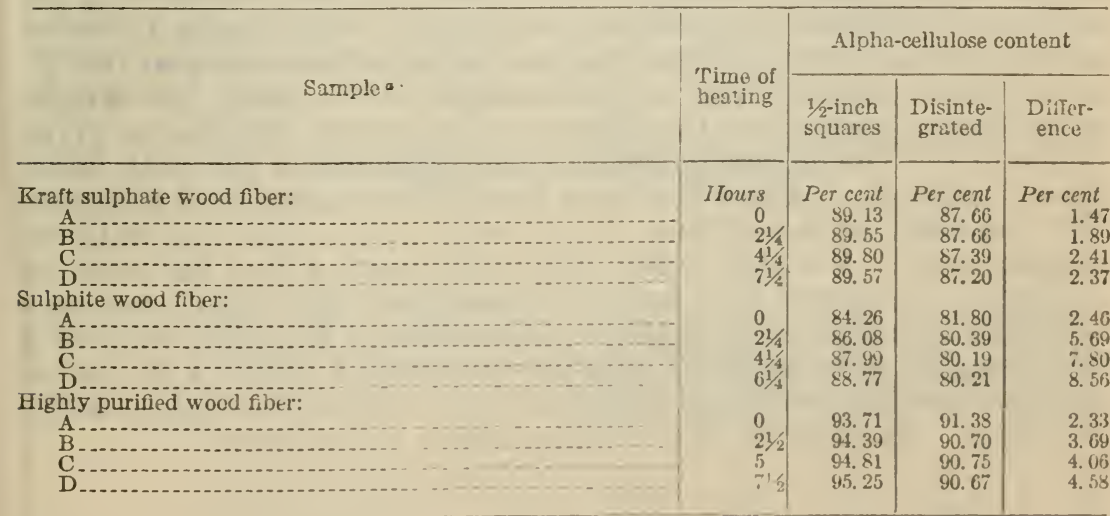

- The sample designations of A, B. C, and D refer to the same stock besten different lengths of time as indicated.

${ }^{10}$ M. B. Shaw, G. W. Bicking, and L. W. Snyder. The Preparation of Fiber Test Sheets, B. S. Jour. Research, 5, (RP 190), pp. 105-114; July, 1930. 
These results show that as the hardness of the paper increases the difference between the values obtained as the alpha-celulose contents of the two forms of the sample increases. The measured value of the alpha-cellulose content of the paper in the ground form changes very little as the hardness of the paper increases. This change is toward a decrease of the value of the alpha-cellulose content, and probably results from chemical changes in the fiber during the beating process. On the other hand, the value obtained for the alpha-cellulose content of the paper in the form of squares increases to a marked extent as the paper increases in hardness. This large increase could hardly be ascribed to any other cause than incomplete reaction of the reagents with the paper. Inasmuch as the fibers of most papers are hydrated to some extent, and as the hardness and resistance to liquids are further increased by engine and surface sizing, these data show that papers must be reduced to a fibrous condition by some such means as grinding to insure maximum reaction in the alpha-cellulose determination.

A grinder similar to the one described under "Preparation of the Sample" is recommended. However, there are several forms of grinders in use, and any of them which will reduce the paper to a fibrous condition without the formation of lumps, without heating the paper, and without excessively bruising and crushing the fibers should be satisfactory.

'The solubility of the nainsook filter cloth in the alkali was investigated. In the alpha-cellulose determination the $100 \mathrm{ml}$ of $17.5 \mathrm{per}$ cent sodium hydroxide used for the mercerization are diluted with $250 \mathrm{ml}$ of water before the mixture is filtered. Thus the concentration of the strongest alkali coming in contact with the filter cloth is about 5.7 per cent. Allkali of this concentration is in contact with the filter cloth for a few minutes only. To find the change of the weight of the filter cloth during a determination, a piece of the nainsook of the size used in the determination was thoroughly washed with warm water and dried to constant weight at $105^{\circ} \mathrm{C}$. It was then treated for 10 minutes with 6 per cent sodium hydroxide solution at $20^{\circ} \mathrm{C}$. The cloth and alkali were thrown on a Büchner funnel, and the cloth washed with $750 \mathrm{ml}$ of water at $20^{\circ} \mathrm{C}$., then allowed to soak in 25 per cent acetic acid for five minutes, and finally washed with 1 liter of boiling distilled water. The cloth was then dried in an oven at $105^{\circ} \mathrm{C}$. to constant weight. The original weight of the cloth, the weight after this treatment, and the difference between the weights are given in Tuble 3. The change in weight is the solubility of the cloth under these conditions. $A$ and $B$ refer to two different samples of nainsook. 'The solubility of $B$ is higher than that of $A$, showing that different samples vary. For this reason it is recommended that the cloth be anulyzed, as outlined here, before it is used, and that a cloth having a solubility approximately that of $\Lambda$ be selected. If a cloth such as $A$ were used an error of about 0.03 per cent, based upon a 4 gr. alphacellulose residue, would be introduced into the alpha-cellulose determination. An crror of this magnitude may be neglected. 
TABLE 3.-Change of the weight of the filter cloth during the alpha-cellulose determination

\begin{tabular}{|c|c|c|c|c|c|c|c|}
\hline Sample 1 No. & $\begin{array}{l}\text { Weight of } \\
\text { the cloth } \\
\text { before } \\
\text { treatment }\end{array}$ & $\begin{array}{l}\text { Weight of } \\
\text { the cloth } \\
\text { after treat- } \\
\text { mont }\end{array}$ & $\begin{array}{l}\text { Change of } \\
\text { the weight } \\
\text { of the cloth } \\
\text { during the } \\
\text { treatment }\end{array}$ & Sample 1 No. & $\begin{array}{l}\text { Weight of } \\
\text { the cloth } \\
\text { before } \\
\text { treatment }\end{array}$ & $\begin{array}{l}\text { Weight of } \\
\text { tho cloth } \\
\text { after treat- } \\
\text { ment }\end{array}$ & $\begin{array}{l}\text { Chango of } \\
\text { the weight } \\
\text { of the cloth } \\
\text { during the } \\
\text { treatment }\end{array}$ \\
\hline $\begin{array}{l}A 1 \ldots \\
A 2 \ldots \\
A 3 \ldots\end{array}$ & $\begin{array}{l}g \\
0.3174 \\
.3172 \\
.3123\end{array}$ & $\begin{array}{l}g \\
0.3161 \\
.3160 \\
.3107\end{array}$ & $\begin{array}{l}g \\
0.0013 \\
.0012 \\
.0016\end{array}$ & $\begin{array}{l}\text { B1.- } \\
\text { B2.- } \\
\text { B3.. }\end{array}$ & $\begin{array}{l}\stackrel{g}{0.2806} \\
.2742 \\
.2778\end{array}$ & $\begin{array}{l}g \\
0.2772 \\
.2706 \\
.2751\end{array}$ & $\begin{array}{l}g \\
0.0034 \\
.0036 \\
.0027\end{array}$ \\
\hline
\end{tabular}

1 Samples A and B were two different pieces of nainsook. Three analyses of each were made.

To make the value obtained for the alpha-cellulose content independent of the amount of sizing and filling materials, it is necessary to correct the weight of the sample analyzed by subtracting the weights of these materials which the sample contains. The difference between the value of the alpha-cellulose content obtained when corrections are made for these materials and the value obtained when they are disregarded is given in the eighth column of Table 4. This difference is appreciable and shows that the basis of calculation of the alphacellulose content should be the weight of the fibrous material in the paper and not the weight of the paper itself. If the weight of the paper is used as the basis of calculation the measured alpha-cellulose content will vary as the amount of filler and sizing material in the paper varies. When the calculation of the alpha-cellulose content is made in this manner the assumption is made that the sizing materials are completely removed by the reagents. This assumption is not strictly valid, as the data in Table 4 show that small amounts of rosin and glue remain in the alpha-cellulose residues. The difference between the calculated value of the alpha-cellulose content when the weight of the residue is corrected for the sizing materials it contains and the value calculated when they are disregarded is given in the last column of Table 4. This difference is small, varies but slightly among the different samples, and for most purposes may be neglected. If a high degree of accuracy is desired, the residues may be analyzed for sizing materials and the corrections applied. However, the alphacellulose residues of loaded papers must always be analyzed for mineral matter and the weights of the residues corrected, owing to the large amount of loading material present in the residues.

TABLE 4.-Data showing magnitude of corrections for sizing materials in papers and in alpha-cellulose residues from them

\begin{tabular}{|c|c|c|c|c|c|c|c|c|c|}
\hline \multirow[b]{2}{*}{ Sample No. } & \multirow[b]{2}{*}{$\begin{array}{c}\text { Rosin } \\
\text { in } \\
\text { sample }\end{array}$} & \multirow[b]{2}{*}{$\begin{array}{l}\text { Glue in } \\
\text { sample }\end{array}$} & \multirow[b]{2}{*}{$\begin{array}{l}\text { Rosin } 1 \\
\text { in alpha- } \\
\text { cellulose } \\
\text { residues }\end{array}$} & \multirow[b]{2}{*}{$\begin{array}{l}\text { Gluo' in } \\
\text { alpha- } \\
\text { cellulose } \\
\text { residues }\end{array}$} & \multicolumn{5}{|c|}{ Alpha-cellulose content } \\
\hline & & & & & $\begin{array}{l}\text { Not cor- } \\
\text { rected for } \\
\text { sizing ma- } \\
\text { terials in } \\
\text { sample or } \\
\text { residue }\end{array}$ & $\begin{array}{c}\text { Corrected } \\
\text { for sizing } \\
\text { materials } \\
\text { in sample } \\
\text { but not in } \\
\text { residue }\end{array}$ & $\begin{array}{l}\text { Differ- } \\
\text { ence due } \\
\text { to correc- } \\
\text { tion for } \\
\text { sizing ma- } \\
\text { terials in } \\
\text { sample }\end{array}$ & $\begin{array}{c}\text { Corrected } \\
\text { for sizing } \\
\text { materials } \\
\text { in sample } \\
\text { and resi- } \\
\text { due }\end{array}$ & $\begin{array}{l}\text { Differ- } \\
\text { ence due } \\
\text { to correc- } \\
\text { tions for } \\
\text { sizing in } \\
\text { residue }\end{array}$ \\
\hline & $\begin{array}{c}\text { Per cent } \\
2.50 \\
1.20 \\
1.70\end{array}$ & $\begin{array}{c}\text { Per cent } \\
3.68 \\
2.19 \\
\end{array}$ & $\begin{array}{r}\text { Per cent } \\
0.11 \\
.08 \\
.10\end{array}$ & $\begin{array}{r}\text { Per cent } \\
0.16 \\
.16\end{array}$ & $\begin{array}{r}\text { Per cent } \\
83.78 \\
85.44 \\
78.63\end{array}$ & $\begin{array}{r}\text { Per cent } \\
89.34 \\
88.45 \\
80.00\end{array}$ & $\begin{array}{r}\text { Per cent } \\
5.56 \\
3.01 \\
1.37\end{array}$ & $\begin{array}{r}\text { Per cent } \\
89.06 \\
88.19 \\
79.68\end{array}$ & $\begin{array}{r}\text { Per cent } \\
0.28 \\
.26 \\
.32\end{array}$ \\
\hline
\end{tabular}

1 Percentages of rosin and glue in the alpha-cellulose residues were calculated on the oven-dry weight of the sample before mercerization. 
In 1929, the cellulose division of the American Chemical Society published a tentative standard method for the determination of alpha cellulose. ${ }^{11}$ This method gives very satisfactory results when applied to pulps, but it is unsuitable for the analysis of papers because of the form in which the sample is used. This method comes from an authoritative source, and will probably be used to a large extent by cellulose investigators. There will, therefore, be many instances when it will be necessary to compare the results obtained by the use of the American Chemical Society method with those obtained by the use of a morc specialized method, such as the one described in this article for the analysis of papers, and it is desirable that the two methods give results in close agreement. The greatest difference betwcen the bureau procedure and that recommended by the American Chemical Society is the difference in the form of the sample. The American Chemical Society method specifies that the material be analyzed in the form of one-half-inch squares, whereas the bureau method specifies that the material be reduced to a fibrous condition before analysis for reasons previously discussed. Otherwise the differences between the two methods are slight. The ratio of alikali to sample in the two methods does not differ sufficiently to cause much difference in the results. The mercerization periods differ, being 30 minutes in the bureau procedure and 45 minutes in the American Chemical Society method. Most methods have a 30-minute mercerization period, and this time was chosen for the bureau procedure so that it would conform as far as practicable with the existing methods. In developing the American Chemical Society method the committee at first suggested a period of 30 minutes, but later changed this to 45 minutes in order to allow more time for the maceration of troublesome materials. Such difficulties are not encountered when the bureau procedure is used, as all materials macerate readily after being ground. The greater length of the mercerization period of the American Chemical Society method should not cause any considerable difference in the results obtained with it and those obtained with the burean method, but the time required for a determination is somewhat longer. The methods of filtering used in the two procedures differ, but both are rapid and efficient and should cause no difference in the results. The method used in the bureau procedure, filtering through a fine cotton cloth on a Büchner funnel, is the more rapid of the two. The removal of the alkali is accomplished in much the same manner in the two methods. Both specify that water at $20^{\circ} \mathrm{C}$. shall be used and that the mat shall soak in dilute acetic acid for five minutes. The volume and concentration of the acetic acid are greater in the bureau method, but this should causc no difference in the results. The method for the removal of the acetic acid used in the bureau procedure, washing with 1 liter of boiling water, is as efficient as the method used in the American Chemical Society procedure, washing with water at $20^{\circ} \mathrm{C}$. until the filtrate is no longer acid to litmus, and is much less time consuming. A comparison of the results obtained with the two methods is given in Table 5. One variation was made in the American Chemical Society method in that the sample was ground before use. Otherwise the two methods

11 Determination of Alpha-Cellulose, Report of Work of Subcommittee 2 of the Division of Cellulose Cal Section, 1, p. 52; 1920 . 
were followed in detail. The data in Table 5 show that results obtained by the two methods agree very well when the determinations are made on ground samples. The bureau method, however, is somewhat more simple and more rapid than the American Chemical Society method.

TABLE 5.-Comparison of the Bureau of Standards method with the tentative method of the American Chemical Society

\begin{tabular}{|c|c|c|c|c|c|c|c|}
\hline \multirow{2}{*}{ Sample No. } & \multicolumn{3}{|c|}{ Bureau of Standards mothod } & \multicolumn{3}{|c|}{$\begin{array}{l}\text { American Chemical Socioty } \\
\text { method }\end{array}$} & \multirow{2}{*}{$\begin{array}{l}\text { Differ- } \\
\text { ence } \\
\text { between } \\
\text { methods }\end{array}$} \\
\hline & $\begin{array}{l}\text { Alpha } \\
\text { cellulos } \theta\end{array}$ & A verage & $\begin{array}{l}\text { Varia- } \\
\text { tion }\end{array}$ & $\begin{array}{l}\text { Alpha } \\
\text { collulose }\end{array}$ & A verage & $\begin{array}{l}\text { Varia- } \\
\text { tion }\end{array}$ & \\
\hline 11. & $\left\{\begin{array}{r}\text { Per cent } \\
88.43 \\
98.25\end{array}\right.$ & $\left\{\begin{array}{r}\text { Per cent } \\
98.34\end{array}\right.$ & $\begin{array}{r}\text { Pcr cent } \\
0.18\end{array}$ & $\left\{\begin{array}{r}\text { Per cent } \\
98.54 \\
98.44\end{array}\right.$ & $\left\{\begin{array}{r}\text { Per cent } \\
98.49\end{array}\right.$ & $\begin{array}{r}\text { Per cent } \\
0.10\end{array}$ & $\begin{array}{r}\text { Per cent } \\
0.15\end{array}$ \\
\hline 12. & $\left\{\begin{array}{l}90.70 \\
90.82\end{array}\right.$ & 90.76 & .12 & $\left\{\begin{array}{l}90.51 \\
90.74\end{array}\right.$ & 90.63 & .23 & .13 \\
\hline 13. & $\left\{\begin{array}{l}90.71 \\
90.77\end{array}\right.$ & 90.74 & . $0 \hat{x}$ & $\begin{array}{l}90.67 \\
90.71\end{array}$ & 90.69 & .04 & .05 \\
\hline 14 & $\begin{array}{l}85.30 \\
85.11\end{array}$ & 85.21 & .19 & $\begin{array}{l}84.83 \\
84.98\end{array}$ & 84. 91 & .15 & .30 \\
\hline
\end{tabular}

The bureau procedure is equally applicable to the analysis of pulps, although designed primarily for paper testing. If pulps are to be analyzed the sample should be ground in the same manner as are papers, if the alpha-cellulose contents of pulps and papers made therefrom are to be compared.

\section{THE DETERMINATION OF THE COPPER NUMBER OF PAPER}

\section{DEFINITION OF THE COPPER NUMBER AND ORIGIN OF THE METHOD}

The copper number is defined as the number of grams of copper in the cuprous oxide precipitated from an alkaline solution of cupric hydroxide under certain specified conditions by $100 \mathrm{~g}$ of cellulose material. The method for the determination of the reducing action of cellulose materials on alkaline copper solutions was originated by Schwalbe. ${ }^{12}$ His method employed Fehling solution and the reduced copper was determined electrolytically after being dissolved in nitric acid. Later this method was modified to include a correction for the bivalent copper absorbed by the cellulose and to exclude as far as possible the correction necessary for the autoreduction of the Fehling solution. ${ }^{13}$ To avoid the correction for the bivalent copper absorbed by the cellulose Hägglund, ${ }^{14}$ and Knecht and Thompson ${ }^{15}$ further modified Schwalbe's method by determining the reduced copper directly. The reduced copper is dissolved in an acidified solution of ferric alum and the copper determined by oxidizing the resulting ferrous solution back to the ferric state by means of standardized potassium permanganate. Staud and Gray ${ }^{16}$ stated that the auto-

12 Schwalbe, Ber., 40, p. 4523; 1907.
13 Schwalbe, Robinoff, and Schulze, in Robinoff's Dissertation, Darmstadt, 1912, and Schulze's Dissertation, Darmstadt, 1910 .

14 Hägglund, Papierfabrikant, 17, p. 301; 1219.

15 Knecht and Thompson, J. Soc. Dyers and Colorists, 36, p. 255; 1820.

16 Staud and Gray, Ind. and Eng. Chom., 17, P. 741; 1925. 
reduction of the Fehling solution can be reduced to a negligible amount, and that a minimum blank is obtainable if certain proportions of the copper sulphate and alkaline tartrate solutions are used. They also studied the effect of time and temperature of heating, and proposed a modification of the Schwalbe method which has found wide applicability. Later Scribner and Brode ${ }^{17}$ developed modifications especially applicable to the determination of the copper number of paper using a modification of the Staud and Gray method for reducing the solution and the method of Gault and Mukerji ${ }^{18}$ for determining the precipitated cuprous oxide. They also subjected the sample to mechanical grinding in order to obtain uniform reaction.

All of the methods described above employ Fehling solution as the copper-containing reagent, all are subject to the inaccuracy caused by the autoreduction of the solutions, and all involve great care and skill to reduce this to a minimum. In 1921 Braidy, ${ }^{19}$ and Koehler and Marqueyrol ${ }^{20}$ described a method in which the alkalinity of the solution is obtained by the use of a sodium carbonate-sodium bicarbonate solution instead of the alkaline tartrate. The lower alkalinity of this solution is designed to prevent the alteration of the ccllulose and autoreduction of the solution. Clibbens and Geake ${ }^{21}$ thoroughly investigated this method and found it to be very satisfactory in detcrmining the extent of oxidation of cotton by acids and oxidizing agents. They recommended its use because of the almost negligible blank obtained on the reagents, because of its accuracy and the reproducibility of the results and because the solution is less alkaline than Fehling solution and is therefore less likely to alter the reducing substances in the cellulose.

After the work of Scribner and Brode in 1927, the Bureau of Standards employed their method for the determination of the copper number of papers. The method was used for some time, but considerable trouble was expericnced with the autoreduction of the solution and in duplicating results. (See Table 6 and 7.) Various means were tricd to avoid these difficulties, such as using carefully purified reagents, agitating the reaction mixture in various ways during the heating, and using carefully regulated temperature baths. Although some of these were advantageous there was still an appreciable blank determination and the desired accuracy could not always be obtained. It was finally decided to use the method of Braidy.

This method has been successfully adapted, with a few minor modifications, to the determination of the copper number of paper. 'The method is thoroughly described by the authors and by Clibbens and Geake, ${ }^{22}$ but will be repeated here. The cuprous oxide is determined by the method of Gault and Mukerji. ${ }^{23}$

\section{PREPARATION OF THE SOLUTIONS}

The alkaline copper solution is made up in two parts, which are mixed just before use.

If Seribner and Brode, B. S. Tech. Papers, 22, No. 354; 1927.

in (ianlt and Mukerji, Comp. rend., 175, p. 711; 1924.

iv Brairly, Rov. gén. Mat. Col., 25, p. 35; 1921.

20 Konhler and Marjueyrol, Mem. Poudres, 18, p. 73; 1921.

21 Clibbens and (joake, J. Textile Inst., 15, p. T31; 1924.

a Sico footnote 21 .

a see footnoto is. 
Solution A:

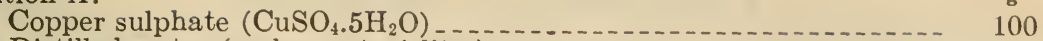

Solution B:

Sodium bicarbonate

Sodium carbonate $\left(\mathrm{Na}_{2} \mathrm{CO}_{3} \cdot 10 \mathrm{H}_{2} \mathrm{O}\right)$

Distilled water (make up to 1 liter).

The reagents should be of $\mathrm{cp}$ grade and the solutions filtered before using.

For the determination of the cuprous oxide a solution of phosphomolybdic acid is used, which is made up as follows:

Sodium molybdate $\left(\mathrm{Na}_{2} \mathrm{MoO}_{4} \cdot 2 \mathrm{H}_{2} \mathrm{O}\right) \ldots$

Phosphoric acid, 83 per cent

Sulphuric acid, 95 per cent_... 275

Distilled water

\section{PROCEDURE}

Weigh accurately approximately $1.5 \mathrm{~g}$ of the paper sample, prepared as described in Section II, and place in a $125 \mathrm{ml}$ Pyrex Erlenmeyer flask. Run $5.0 \mathrm{ml}$ of solution A from a burette into $95 \mathrm{ml}$ of solution B, shake well and bring the mixture to a boil. Pour the boiling solution over the sample and stir thoroughly. Stopper the flask with a loosely fitting glass bulb. A flat-topped glass stopper, the stem of which is slightly smaller than the neck of the flask, is suitable for this purpose. Place the flask in a steam bath or some other constant temperature bath at about $100^{\circ} \mathrm{C}$. and allow it to remain there three hours. The contents of the flask should be shaken occasionally during this period. At the end of the heating period filter the contents of the flask through a good grade of filter paper having a low porosity, ${ }^{24}$ using a Büchner funnel and suction. Wash with $100 \mathrm{ml}$ of 5 per cent sodium carbonate solution and then with $250 \mathrm{ml}$ of boiling distilled water. Transfer the fiber and filter paper to a $400 \mathrm{ml}$ beaker, add $25 \mathrm{ml}$ of the phosphomolybdic acid solution. and macerate well with a flattened glass rod. Allow the acid to act for a few minutes, then add $100 \mathrm{ml}$ of cold distilled water and filter again on a Büchner funnel with suction. Wash the fiber with distilled water until all of the blue color has been removed. To avoid an excessive volume of wash water, the washing is best accomplished by disconnecting the suction, adding a small volume of water and allowing the fiber to soak in it for a few minutes. This is then removed by means of the suction and the washing repeated with another small volume of water. Titrate the blue filtrate with $N / 20$ potassium permanganate to a faint pink.

The copper number may be calculated from the following formula:

Copper number $=\frac{6.357 \times\left(\text { total } \mathrm{ml} \mathrm{KMnO}_{4}-\mathrm{ml} \mathrm{KMnO}_{4} \text { for blank }\right) \times N}{W}$

where $N$ is the normality of the potassium permanganate and $W^{\top}$ is the weight in grams of the sample used after corrections have been applied for noncellulosic constituents as described in Section II. The blank correction is the volume of $\mathrm{KMnO}_{4}$ necessary to color the solution a faint pink.

24 A Whatman No. 42 filter paper is suitable for this purpose. 


\section{LISCUSSION OF THE METHOD}

A complete study of the method has been made by Clibbens and Geake. For this reason the work described in this article was limited to a study of the application of the Braidy method to paper analysis and a comparison of the Braidy method with a method employing Fehling solution as the copper containing reagent. The results of the comparison are given in Tables 6 and 7. These results show that if the duplicate analyses on one sample are made at different times the Braidy method has an average error only one-eighth as large as the method employing Fehling solution. If duplicate analyses are made at the same time the Braidy method has an average error one-third as large as the Fehling solution method. The ratios of the Braidy values to the Fehling solution values average approximately 1.3. This ratio has been given values from 1.15 to 1.5 by various investigators. Considering the wide variety of papers studied the ratios agree rather well, and as an approximation it may be said that:

Copper number (Braidy method) $=1.3 \times$ copper number (Fehling solution method).

TABLE 6.-Copper number of papers; duplicate analyses made at different times

\begin{tabular}{|c|c|c|c|c|c|c|c|c|c|c|}
\hline \multirow{2}{*}{ Sample No. } & \multirow{2}{*}{$\begin{array}{l}\text { Fiber com- } \\
\text { position }{ }^{1}\end{array}$} & \multicolumn{4}{|c|}{$\underset{\text { tion method }{ }^{2}}{\text { Copper number Fehling solu- }}$} & \multicolumn{4}{|c|}{$\begin{array}{l}\text { Copper number; Braidy } \\
\text { method }\end{array}$} & \multirow{2}{*}{$\begin{array}{r}\text { Ratio } \\
\text { B:F.S. }\end{array}$} \\
\hline & & I & II & $\begin{array}{c}\text { Aver- } \\
\text { age }\end{array}$ & $\begin{array}{l}\text { Devia- } \\
\text { tion from } \\
\text { average }\end{array}$ & I & II & $\begin{array}{l}\text { Aver- } \\
\text { age }\end{array}$ & $\begin{array}{l}\text { Devia- } \\
\text { tion from } \\
\text { average }\end{array}$ & \\
\hline iii & Per cent & & & 0,47 & Per cent & & & & Per cent & \\
\hline 100 & $100 \mathrm{Y} . \mathrm{W} . \mathrm{F}$ & 1.11 & 1.08 & $\begin{array}{l}0.48 \\
1.10\end{array}$ & 1.4 & 1.30 & 1.32 & $\begin{array}{l}0.03 \\
1.31\end{array}$ & 0.8 & \\
\hline$a a_{-}$ & 100 P. WV. F & 1. 22 & 1.20 & 1. 21 & .8 & 1.65 & 1.67 & 1.66 & .6 & 1.4 \\
\hline $102^{-}$ & $100 \mathrm{~S}$ & 3. 13 & 3.44 & 3. 29 & 4.8 & 4.61 & 4. 60 & 4. 61 & .1 & 1.4 \\
\hline (1)- & $100 \mathrm{~S}$ & 3.75 & 3.94 & 3.85 & 2.5 & 5. 08 & 5. 12 & 5.10 & .4 & 1. \\
\hline 8 & $100 R$. & .68 & .78 & .73 & 6.9 & .82 & .81 & .82 & .6 & 1. \\
\hline . & $100 \mathrm{R}-$ & .94 & 1.02 & .98 & 4.1 & 1.23 & 1. 25 & 1.24 & .8 & 1. \\
\hline 119 & $100 \mathrm{R}$. & 1.36 & 1.42 & 1. 39 & 2. & 1.71 & 1. 68 & 1.70 & .9 & 1. \\
\hline & $100 \mathrm{R}$. & .53 & .62 & .58 & 7.8 & 1. 07 & 1. 05 & 1. 06 & .9 & 1. \\
\hline 130 & $100 \mathrm{R}$. & .94 & .94 & .94 & & 1. 32 & 1. 32 & 1. 32 & 0 & \\
\hline & $100 \mathrm{R}$. & .85 & .90 & .88 & 2.9 & 1. 13 & 1. 12 & 1.13 & .5 & 1 \\
\hline 126 & $100 \mathrm{~K}$. & 1. 03 & 1. 20 & 1. 12 & 7.6 & 1.56 & 1.48 & 1. 52 & 2.6 & 1 \\
\hline $127-$ & $100 \mathrm{R}-$ & .86 & .66 & .76 & ${ }^{3} 13.1$ & .90 & .90 & .90 & 0 & 1.2 \\
\hline & 11 & 1. 39 & .93 & 1.16 & ${ }^{3} 19.8$ & 1.66 & 1. 70 & 1. 68 & 1.2 & \\
\hline A vernge & & & & & 5.7 & & & & .7 & 1.3 \\
\hline
\end{tabular}

1 The fiber composition is denoted as follows: $\mathrm{R}=\mathrm{rag}, \mathrm{P} . \mathrm{W} . \mathrm{F} .=$ highly-purified wood fiber, $\mathrm{S}=$ sulphite wood flher.

2 'The Fehling solution method was that described by Scribner and Brode. (See footnote 17, p. 614.)

Despite the unusunlly wide deviations it was decided to include these results in the average. 
TABLE 7.-Copper number of papers; duplicate analyses made al the same time

\begin{tabular}{|c|c|c|c|c|c|c|c|c|c|c|}
\hline \multirow{2}{*}{ Sample No. } & \multirow{2}{*}{$\begin{array}{l}\text { Fiber com- } \\
\text { position } 1\end{array}$} & \multicolumn{4}{|c|}{$\begin{array}{c}\text { Copper number; Fehling solu- } \\
\text { tion method }{ }^{2}\end{array}$} & \multicolumn{4}{|c|}{$\begin{array}{l}\text { Copper number; Braidy } \\
\text { method }\end{array}$} & \multirow{2}{*}{$\begin{array}{c}\text { Patio } \\
B: F . S .\end{array}$} \\
\hline & & I & Il & $\begin{array}{l}\text { Aver- } \\
\text { age }\end{array}$ & $\mid \begin{array}{c}\text { Devia- } \\
\text { tion from } \\
\text { average }\end{array}$ & I & II & $\begin{array}{l}\text { A ver- } \\
\text { ago }\end{array}$ & $\begin{array}{c}\text { Devia- } \\
\text { tion from } \\
\text { average }\end{array}$ & \\
\hline 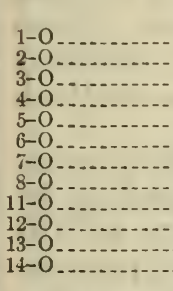 & $\begin{array}{l}\text { Per cent } \\
100 \mathrm{R} \\
50 \mathrm{~S}-50 \mathrm{~S} 0 \\
100 \mathrm{R} \\
100 \mathrm{~S} \\
100 \mathrm{~S} \\
50 \mathrm{R}-50 \mathrm{~S} \\
100 \mathrm{R} \\
100 \mathrm{R} \\
40 \mathrm{~S}-60 \mathrm{~S} \\
100 \mathrm{R} \\
100 \mathrm{R} \\
100 \mathrm{R}\end{array}$ & $\begin{array}{l}1.77 \\
2.52 \\
1.66 \\
3.54 \\
2.27 \\
1.09 \\
1.55 \\
1.11 \\
4.04 \\
3.53 \\
4.32 \\
2.19 \\
\end{array}$ & $\begin{array}{l}1.81 \\
2.25 \\
\text { 1. } 51 \\
\text { 3. } 53 \\
2.19 \\
\text { 1. } 12 \\
1.40 \\
\text { 1. } 13 \\
\text { 3. } 83 \\
\text { 3. } 56 \\
4.24 \\
2.08 \\
\end{array}$ & $\begin{array}{l}1.79 \\
2.38 \\
1.59 \\
\text { 3. } 53 \\
2.23 \\
1.11 \\
1.47 \\
1.12 \\
3.93 \\
3.54 \\
4.28 \\
2.13 \\
\end{array}$ & \begin{tabular}{|r|} 
Per cent \\
1.1 \\
5.7 \\
4.7 \\
.2 \\
1.8 \\
1.4 \\
5.1 \\
.9 \\
2.6 \\
.4 \\
.9 \\
2.6 \\
\end{tabular} & $\begin{array}{l}2.55 \\
\text { 3. } 24 \\
2.10 \\
\text { 4. } 50 \\
\text { 3. } 02 \\
\text { 2. } 31 \\
\text { 1. } 79 \\
\text { 1. } 41 \\
4.66 \\
4.38 \\
5.61 \\
2.54 \\
\end{array}$ & $\begin{array}{l}2.52 \\
3.23 \\
2.10 \\
4.37 \\
2.91 \\
2.31 \\
1.81 \\
1.39 \\
4.75 \\
4.30 \\
5.70 \\
2.55 \\
\end{array}$ & $\begin{array}{l}2.53 \\
3.23 \\
2.10 \\
4.47 \\
2.96 \\
2.31 \\
1.80 \\
1.40 \\
4.70 \\
4.34 \\
5.65 \\
2.55 \\
\end{array}$ & \begin{tabular}{|c|} 
Per cent \\
0.6 \\
.2 \\
0 \\
2.1 \\
1.9 \\
0 \\
.6 \\
.7 \\
.9 \\
.9 \\
.8 \\
.2 \\
\end{tabular} & $\begin{array}{l}1.4 \\
1.4 \\
1.3 \\
1.3 \\
1.3 \\
2.1 \\
1.2 \\
1.3 \\
1.2 \\
1.2 \\
1.3 \\
1.2 \\
\end{array}$ \\
\hline Aver & & & & & 2.3 & & & & .7 & 1.3 \\
\hline
\end{tabular}

1 The fiber composition is denoted as follows: $R=$ rag; $S=$ sulphite wood fiber; $S o=$ soda wood fiber

2 The Fehling solution method was that described by Scribner and Brode. (See footnote 17, p. 614.)

The results obtained on the papers tested showed no relation between the type of fiber and the value of this ratio.

Three modifications of the Braidy method, as described by Clibbens and Geake, were made so that the method would be more applicable to paper analysis. The form of the sample was not specified by these investigators, doubtlessly because they were working with raw cotton which may be analyzed in its naturăl form. A specification for the form in which the sample must be used has been included in the present procedure. A second modification is a change of the weight of the sample from 2.5 to $1.5 \mathrm{~g}$. The third modification is the use of phosphomolybdic acid instead of ferric alum for the determination of the cuprous oxide.

As was the case in the alpha-cellulose determination the greatest departure from the usual methods is the disintegration of the sample. Such a procedure appears to be necessary in the copper number determination for the same reason that it is necessary in the alphacellulose determination; that is, to insure complete reaction. The copper numbers of papers in the form of squares are usually lower than those obtained when the paper is disintegrated, although this is not always the case. Jonas ${ }^{25}$ recommends the use of benten cellulose. Other investigators recommend the squares. The copper number depends upon the number of reducing groups in the material and the completeness of the reaction between these groups and the reagents. Therefore, the method of preparation of the sample should be immaterial if it does not alter the number of reducing groups, and if it produces a form of the sample which will insure complete reaction. Grinding the sample as described in Section II reduces the material to such a condition that it can all be acted upon by the reagents, and if the grinding is done without heating the material the number of reducing groups should remain unaltered. Also, the precipitated

2s Jonas, Z. angew. Chem., 41, pp. 960-961; 1928. Abstracted in The Paper Makers' Monthly J., 11, Nov. 15,1928 .

$43324^{\circ}-31-7$ 
cuprous oxide is much more easily removed from a disintegrated sample than it is from hard, compact squares.

The Braidy method, as described by Clibbens and Geake, uses $2.5 \mathrm{~g}$ of sample, but in the method described here for the analysis of paper the weight of the sample is changed to $1.5 \mathrm{~g}$. This is because there is insufficient copper in the volume of solutions used to account for all of the reducing power of some papers when the weight of the sample is $2.5 \mathrm{~g}$. Clibbens and Geake showed that there was a slight increase in copper number as the weight of the sample was increased. However, as the $2.5 \mathrm{~g}$ sample is an arbitrary. weight another arbitrary weight was used which would give the desired range for the method. This is suggested by Clibbens and Geake.

The determination of the cuprous oxide by means of phosphomolybdic acid is used because of the assurance of complete washing by the removal of all of the blue color and because of the very definite end point when the blue solution is titrated with potassium permanganate. The blue color changes from dark blue, to green, to colorless and finally to pink as the potassium permanganate is added. Ferric alum is equally good as an oxidizing agent for the cuprous oxide, but we believe the phosphomolybdic acid is easier to work with. The two give practically the same results, as is shown in Table 8.

TABLE 8.-Comparison of methods for determining the cuprous oxide in the copper number determination

\begin{tabular}{|c|c|c|}
\hline \multirow{2}{*}{ Sample No. } & \multicolumn{2}{|c|}{ Copper number } \\
\hline & $\begin{array}{l}\text { Phosphomo- } \\
\text { lybdic acid }\end{array}$ & $\begin{array}{l}\text { Ferric } \\
\text { alum }\end{array}$ \\
\hline $\begin{array}{l}\text { Blank } \\
1 \\
2 \\
3\end{array}$ & $\begin{array}{r}0.03 \\
.31 \\
.37 \\
3.75\end{array}$ & $\begin{array}{r}0.12 \\
.30 \\
.38 \\
3.77\end{array}$ \\
\hline
\end{tabular}

A variation of the temperature at which the reduced phosphomolybdic acid is titrated between $10^{\circ}$ and $40^{\circ} \mathrm{C}$. has no effect on the results. Cuprous oxide was dissolved in $125 \mathrm{ml}$ of the phosphomolybdic acid solution and the solution made up to $250 \mathrm{ml}$ with water in a volumetric flask. Fifty $\mathrm{ml}$ portions of this solution were made up to $300 \mathrm{ml}$ with water of different temperatures and titrated with potassium permanganate. The results are given in Table 9.

ТАвце 9.-Effect of temperature on the titration in the copper number determination

\begin{tabular}{|c|c|}
\hline $\begin{array}{c}\text { Temperature } \\
\text { of solution } \\
\text { titrated }\left({ }^{\circ} \mathrm{C} .\right)\end{array}$ & $\begin{array}{c}\text { Titre in ml } \\
\text { KMnO4 }\end{array}$ \\
\hline 10 & 10.34 \\
27 & 10.36 \\
40 & 10.32 \\
\hline
\end{tabular}

Clibbens and Geake studied the effect of small changes of the temperature of the reaction upon the copper number. They found that a difference of $1.5^{\circ} \mathrm{C}$. caused a difference of 5 to 10 per cent in 
the copper number. For this reason it is important to control the temperature of the constant temperature bath very carefully. A bath of steam or boiling water is the usual form of constant temperature bath, but the temperature of such a bath varies with the atmospheric pressure, causing a variation in the copper number. For accirate work or when results obtained at different times must be compared, a bath which is not subject to these variations, such as an oil bath with thermostatic control capable of maintaining a temperature constant within $\pm 0.1^{\circ} \mathrm{C}$., should be used.

If pure reagents are used no couprous oxide will be precipitated from them when they are heated for three hours at the temperature of the steam bath. This is clearly shown by the fact that no blue color is formed when reagents treated in this manner are filtered and phosphomolybdic acid is added to the filter paper. However, if the phosphomolybdic added to the filter paper is washed out and filtered as is done when copper numbers are being determined, the resulting filtrate will require about $0.15 \mathrm{ml}$ of $N / 20$ potassium permanganate to color it a faint pink. This volume of potassium permanganate accounts for the blank correction in the formula given in Section IV, part 3.

\section{CONCLUSION}

The methods described in this article for the determination of the alpha-cellulose content and copper number of paper are the methods now being used at the Bureau of Standards. It is not claimed that they are new, but rather that they are further developments of existing methods designed to make them more suitable for paper testing. While it is recognized that several steps in the procedures might be further investigated to advantage, the methods described herein give results which can be readily duplicated, and they are less time consuming than the methods formerly used. Grinding the sample, as recommended herein, is particularly important when analyzing paper.

WaShington, January 27, 1931. 